\title{
Supply-Side Hurdles in Internet B2C E-Commerce: An Empirical Investigation
}

\author{
Michael Tow Cheung, Member, IEEE, and Ziqi Liao, Senior Member, IEEE
}

\begin{abstract}
Given Hong Kong's special circumstances of small physical size, advanced infrastructure, and low shopping cost, a survey is designed under which supply-side problems in Internet business-to-consumer (B2C) e-commerce are indirectly revealed by responses on the demand side. Difficulties arising from the reluctance to answer questionnaires on the part of e-firms wary about trade and innovation secrets and their small number at the outset are thereby overcome. Survey data on demand-side obstacle factors in the form of perceived low e-shopping comparability, e-shopping inconvenience, e-transaction insecurity, and poor Internet privacy, together with orientation toward social interaction and low awareness on the part of consumers, translate into information on notionally matching supply-side hurdles. Regression analysis and hypothesis testing indicate statistical significance for the above hurdle factors in terms of impact on individual unwillingness to shop online. These results add to the inductive basis for future research into a general demand-supply theory of Internet B2C e-commerce and offer an empirically-grounded position against which the effects of later supply-side changes can be evaluated. Useful information also follows for engineer-managers seeking to compare marginal improvements in supply-side problems, particularly in the form of estimated substitution ratios.
\end{abstract}

Index Terms-Consumer perceptions, demand-side obstacle factors, empirical results, Internet business-to-consumer (B2C) e-commerce, notionally matching supply-side hurdles, thought-experiment-based survey, unwillingness to e-shop.

\section{INTRODUCTION}

H ONG KONG can be regarded as a typical example of a technologically-following market economy (as defined below) with recently introduced but growing Internet usage. From less than 1.3 million in 1999, the number of Internet users nearly doubled to 2.5 million by mid-2000. This figure accounted for some $50 \%$ of the population aged 12-60, of which, $58 \%$ were male, $63 \%$ were aged between 15 and 29, and $24 \%$ between 30 and $44.15 \%$ of the Internet users were also online shoppers [43], [46]. Though Internet business-to-consumer (B2C) e-commerce is still in the introductory stage, the value of this market is expected to increase from US\$250 million to US $\$ 9$ billion from 2000 to 2004 [18]. Given that information technology (IT) is followed in the sense of being transferred or imported instead of endogenously invented, its availability (and rate of change therein) can be assumed to be

Manuscript received October 18, 2001; revised April 19, 2002. This work was supported by the Hong Kong Baptist University under Research Grant FRG/9900/II-26.

M. T. Cheung is with the School of Economics and Finance, University of Hong Kong, Pokfulam Road, Hong Kong (e-mail: mcheung@econ.hku.hk).

Z. Liao is with the Department of Finance and Decision Science, Hong Kong

Baptist University, Kowloon, Hong Kong (e-mail: zqliao@yahoo.com).

Digital Object Identifier 10.1109/TEM.2003.819649 given in the medium run. We can, therefore, proceed to study the behavior of Internet e-firms with respect to their immediate market environment, free from complications arising from longer-run interactions between business strategy, research and development, and investment directed to embody technological change [28]. Moreover, since consumer products tend to be more standardized at the outset, it is possible to assume that the distorting effects of information asymmetry and "lemon" problems [2] are negligible when interpreting Internet B2C e-market data in the present situation.

Despite the optimistic forecasts, many of Hong Kong's Internet B2C e-firms are already experiencing financial difficulties, the best-known case being perhaps the territory's largest online consumer goods supermarket AdMart. Some commentators have suggested that over-ambitious inventory and leasing arrangements contributed to AdMart's problems, while others have pointed to factors such as inefficient management, a weakly defined business model, computer system problems, poor public relations, unrealistic expectations, lack of sustained investment, supplier-delivery problems, and negative external shocks [17]. Given the world-wide downturn in IT-related business activities and the potential importance of technology transfers in any future recovery, such events lend practical urgency to the question of whether idiosyncratic and empirically significant supply-side barriers exist to deter Internet B2C e-commerce during the crucial "infant market" phase in technologically-following economies. Moreover, since not a few rationalizations have been proposed for the current problems, an empirical investigation of supply-side problems would be useful to support the prioritization of remedial action on the part of Internet e-firms, industrial policy, and the public sector.

Among technologically following market economies, Hong Kong is atypical in a methodologically important aspect. Testing models of Internet B2C e-commerce usually requires statistics on a large number of variables. Since existing studies have predominantly referred to the United States, given its large area and socioeconomic and technological diversity, the task of evaluating the importance of the different determinants and consequences of changes is complicated by the difficulty of discovering data in which complex ceteris paribus conditions are present. On the other hand, because of Hong Kong's small physical size, social homogeneity, advanced infrastructure and banking, the logistics, communications, and payment costs associated with ordinary and Internet-based shopping tend to be low and similar [26], [27]. Such an environment is especially suitable for highlighting the differences qua shopping between the two submarkets in which the buying and 
selling of consumer goods primarily take place (loc. cit.). As a result, supply-side problems facing Internet B2C e-commerce (especially at the outset) can be conveniently evaluated through the introduction of close-substitute situations with traditional firms as given reference points under simple and clearly defined ceteris paribus conditions.

Under consumer sovereignty, online selling would fail unless the performance of Internet e-firms meets with individual expectations and requirements. To test the acceptance of new information technology, an influential analysis originating with Davis [8] and Davis et al. [9] proposed to measure perceptions of usefulness and ease of use on the part of individuals using a given system. The present paper applies the insights of the technology acceptance model (TAM) to the case of Internet B2C e-commerce, appropriately interpreted as a new IT-based avenue through which consumer goods are bought and sold. However, given that the area of interest is supply-side problems, instead of holding the supply environment constant as in the TAM, we allow it to vary within the perceptions of individuals on the demand side. For the same reason, the relevant criteria become perceived unusefulness and perceived difficulty of use, leading thereby to obstacles which reduce willingness to e-shop over the Internet. Given Hong Kong's special circumstances, we proceed to design a survey to elicit information on how negative perceptions of vendor performance and unfavorable shopper characteristics, under the "as if" condition that these obstacle factors are notionally present or allowed to persist in Internet e-firms, would increase the individual's unwillingness to buy from them. Under these assumptions, survey data on demand-side obstacle factors translate into information on notionally matching supply-side hurdles to Internet B2C e-commerce. Since the e-market is yet to be developed to any significant extent, the latter would then represent potential supply barriers, which e-firms must surmount in the immediate future before take-off can occur.

Research into Internet B2C e-commerce must often contend with the reluctance to answer survey questionnaires, especially on the part of firms jealous of trade and innovation secrets. Given the large number of variables involved, empirical testing is likely to be stymied if data for just one of them are not available. At the outset, during the "infant industry" phase, the problem would be aggravated by the small number of Internet e-firms in existence. Under the present approach, these difficulties are overcome by means of a thought experiment-based survey, through which supply-side requirements are indirectly revealed by respondent information on the demand side. In the first place, since individuals were queried about perceived vendor performance and shopper characteristics which if notionally present or are allowed to persist by Internet e-firms would reduce the willingness to buy, it was not necessary to obtain direct responses from the latter. Secondly, given the notional nature of the supply side in our exercise, as long as the sample of consumers is sufficiently representative and large, the small number of Internet e-firms at the outset would not affect the statistical significance of the survey data. Finally, as will be shown in Section IV, the number of variables in the analysis can be reduced by excluding actual demand-side considerations (e.g. price differentials) without compromising the validity of the empirical results in many cases of interest.
We proceed to quantify the different demand-side obstacle factors in terms of the survey data, and to estimate the impact of the translated notionally matching supply-side hurdles on individual intentions not to e-shop over the Internet. By construction, consumer unwillingness emerged from our survey responses as the result of the "as if" presence or persistence in Internet e-firms of negative perceptions regarding e-vendor performance and unfavorable shopper characteristics. In the first exercise , since notionally demand = supply, the initial relationship between unwillingness and perceived (demand-side) obstacle factors is transformed into an ex ante relationship between unwillingness and translated notionally matching supply-side hurdles. With regard to the second exercise, extra-market (taste and cultural) factors are involved. Since exogenous variables enter in both instances, the survey data can be employed to estimate the overall relationship between unwillingness and supply-side hurdles in reduced form without endogenous regressor or simultaneous equation bias.

We found that statistically significant supply-side hurdles to Internet B2C e-commerce exist at the outset, as translated from survey data on demand-side obstacle factors in the form of perceived low shopping comparability, shopping inconvenience, transaction insecurity, and poor privacy, together with orientation toward social interaction and low awareness on the part of consumers. Initiatives to develop the e-market can be usefully guided by the relative empirical importance of these (potential) supply barriers. In particular, an empirically grounded reference position follows from the regression analysis and hypothesis-testing, in terms of which the effects of technological and organizational improvements in e-firms can be compared and interpreted under clearly defined conditions. On a more general level, it is hoped that our empirical results would add inductive support to future research into a general equilibrium demand-supply theory of Internet B2C e-commerce. Finally, lessons can be drawn for applications to the marketing and engineering management of new IT-based consumer products and services, especially by generalizing from the problems studied and approaching them in the order suggested by empirical significance.

\section{HyPOTHESES ON SUPPLY-SidE HuRdLES}

As can be seen from the reference lists in the survey article by Zwass [52] and the textbooks by Kalakota and Whinston [22], Turban et al. [48], and Schnieder and Perry [38], an extensive literature exists on the determinants of success or failure in Internet B2C e-commerce. In particular, Swaminathan et al. [45] investigated adoption factors in the form of information content, transaction security, and privacy safeguards. An alternative approach was proposed by Kyeong and Mee [25], under which satisfaction with and involvement in Internet B2C e-commerce are diminished by detrimental characteristics such as the lack of consumer knowledge. We adapt and extend existing research to identify a set of negative consumer perceptions and shopper characteristics which, if present or allowed to persist in Internet e-firms in the "as if" sense discussed in Section I, would increase individual unwillingness to buy. Under our assumptions, survey data on the demand-side obstacle factors in question-individual perceptions with regard to negative e-vendor 
performance, transaction insecurity and poor privacy, together with orientation toward social interaction and low awareness on the part of shoppers - then translate into information regarding notionally matching supply-side hurdles to Internet B2C e-commerce.

In the remainder of this Section, we present nine hypotheses to empirically evaluate the effects of different supply-side hurdles on individual unwillingness to e-shop over the Internet. The hypotheses are then tested and the results interpreted in Sections III and IV, utilizing survey data obtained under Hong Kong's special circumstances.

\section{A. Poor e-Vendor Performance}

Since individuals would rationally evaluate sellers before buying, Internet B2C e-vendors must demonstrate superior performance over traditional shops in one or more dimensions to be noticed and approached online. The greater the accessibility of the physical market, the easier it would be for individuals to feel dissatisfied with virtual buying. Shopping comparability, particularly as perceived to involve information competitiveness in the sense discussed below, therefore affects Internet $\mathrm{B} 2 \mathrm{C}$ e-commerce to an important degree. According to Zellweger [51] and Tan and Teo [47], the Internet can effectively create and enhance comparative advantage in the dissemination of prices and product information. Since the electronic transmission of information facilitates price comparisons [3], opportunities for competition on the part of online vendors would increase. On the other hand, if these advantages are not exploited so that shopping comparability is perceived to be poor by consumers, the unwillingness to buy would increase. Under our assumptions, survey data on perceived low shopping comparability interpreted as a demand-side obstacle factor translate into information regarding a notionally matching supply-side hurdle facing Internet B2C e-commerce.

Existing research suggests that perceived convenience significantly affects individual decisions to buy online. As measured by Gehrt et al. [11], shopping convenience involves the ease of placing and cancelling orders, of returns and refunds, and timely delivery. Jarvenpaa and Todd [20] describe shopping experience in terms of effort, compatibility, and playfulness. We suggest that effort, especially when it involves ease of operation and ease of searching, placing and cancelling orders, contributes importantly to individual perceptions of e-shopping convenience. Instead, if the e-vendor delivers perceived inconvenience, unfavorable shopping experience is induced and the unwillingness to buy online would increase. Under our assumptions, survey data on perceived shopping inconvenience interpreted as a demand-side obstacle factor then translate into information regarding a notionally matching supply-side hurdle to Internet $\mathrm{B} 2 \mathrm{C}$ e-commerce.

An important vendor characteristic investigated by Jarvenpaa and Todd [20] is customer services, defined to include responsiveness, assurance, reliability, empathy, and tangibility. Of particular interest to the present investigation is the extent to which perceptions of empathy and tangibility affect individual intentions to e-shop over the Internet. Empathy, especially as displayed in during-and after-sale services, can be imagined to increase according to the degree and speed by which the e-vendor is perceived to be able to adapt to customer needs and requirements [29]. The related concept of tangibility refers to whether the e-vendor is perceptually or actually able to replace a real product (as offered in traditional shops) with an appealing and information-rich virtual substitute. Any deficiency in this direction heightens the uncertainty inherent in purchasing something that has yet to be physically experienced, in particular weakening the individual's potential to utilize price and quality assessment as a strategy to reduce transaction risk [49]. In sum, lack of perceived empathy and perceived tangibility tend to weaken individual intentions to shop online. Under our assumptions, survey data on these demand-side obstacle factors would then translate into information regarding two notionally matching supply-side hurdles facing Internet B2C e-commerce.

Zellweger [51] has raised the question of whether the information e-vendors so readily make available over the Internet is ultimately useful in the sense of increasing business volume. Since the answer depends to a large extent on the influence exerted on shopping behavior, it is proposed to investigate whether the perceived uselessness of information supplied through virtual storefronts and displays would increase consumer unwillingness. Survey data on the perceived uselessness of information interpreted as a demand-side obstacle factor then translate under our assumptions into information regarding a notionally matching supply-side hurdle to Internet B2C e-market development.

Under our assumptions, survey data on demand-side obstacle factors in the form of negatively perceived e-vendor characteristics translate into information on notionally matching supply-side hurdles. To empirically evaluate the effects on individual unwillingness to e-shop over the Internet, we propose five hypotheses.

$H 1(a)$. Individual intentions not to shop online are stronger the greater low shopping comparability interpreted as a demand-side obstacle factor is perceived. Translating in terms of the survey data, the notionally matching supply-side hurdle facing Internet B2C e-commerce would then become higher.

$H 1(b)$. Individual intentions not to shop online are stronger the greater shopping inconvenience interpreted as a demand-side obstacle factor is perceived. Translating in terms of the survey data, the notionally matching supply-side hurdle facing Internet B2C e-commerce would then become higher.

$H 1(c)$. Individual intentions not to shop online are stronger the lower empathy interpreted as a demand-side obstacle factor is perceived. Translating in terms of the survey data, the notionally matching supply-side hurdle facing Internet B2C e-commerce would then become higher.

$H 1(d)$. Individual intentions not to shop online are stronger the lower tangibility interpreted as a demand-side obstacle factor is perceived. Translating in terms of the survey data, the notionally matching supply-side hurdle facing Internet B2C e-commerce would then become higher.

$H 1(e)$. Individual intentions not to shop online are stronger the higher uselessness of information interpreted as a demand-side obstacle factor is perceived. Translating in terms of the survey data, the notionally matching supply-side hurdle facing Internet B2C e-commerce would then become higher. 


\section{B. Transaction Insecurity and Privacy Concerns}

According to Jarvenpaa and Todd [20], two types of risk are relevant for individuals e-shopping over the Internet: that which arises from the possibility of monetary and psychic losses following a quickly-induced purchase under incomplete information, and that which arises from the possibility that a product or service would fail to meet expectations. Associated with perceived transaction security in this context is the possibility of losses arising from the improper or unsanctioned use of information transmitted over the Internet [10], [15], [19], [30], [32], [37]. Despite technical advances and innovations in security safeguards such as cryptography, e-authentication, screening, and firewalls, individuals have been discovered to be anxious about buying and paying over a public medium [15], [45], [51].

These observations suggest that a strong obstacle factor is present on the demand side, in the form of individual anxiety over the safety and integrity of transactions and information transmission over the Internet. Indeed, some commentators believe that as a result of negative consumer reaction in this regard, there is a possibility that Internet B2C e-commerce would fail to emerge from the "infant market" stage in the Hong Kong [16]. Under our assumptions, survey data on perceived transaction insecurity translate into information on a notionally matching supply-side hurdle to Internet B2C e-market development. To test its empirical significance, we propose the following hypothesis.

$H 2$. Individual intentions not to shop online are stronger the higher transaction insecurity interpreted as a demand-side obstacle factor is perceived. Translating in terms of the survey data, the notionally matching supply-side hurdle facing Internet B2C e-commerce would then become higher.

Closely related to the above considerations are individual concerns and perceptions regarding privacy in Internet e-shopping. Keen debates have arisen over the technical and economic viability of proposed solutions [6], [7], [13], [14], [23], [31], [33]-[36], [50]. Under our assumptions, survey data on this obstacle factor translate into information regarding a notionally matching supply-side hurdle to Internet B2C e-commerce. To evaluate its empirical significance, we present the following hypothesis.

$H 3$. Individual intentions not to shop online are stronger the greater privacy concerns interpreted as a demand-side obstacle factor are perceived. Translating in terms of the survey data, the notionally matching supply-side hurdle facing Internet B2C e-commerce would then become higher.

\section{Unfavorable Shopper Orientation}

The literature on relationship marketing (e.g. [39]) suggests that consumer characteristics, in particular sociological orientation, would importantly affect the propensity to e-shop over the Internet. According to Bellenger and Kargaonkar [5], shoppers can be classified into recreational and convenience types, with the former being significantly motivated by the social interaction made possible when buying consumer goods. Related research has shown Internet e-shopping to be less attractive, the more individuals regret the diminished social interaction relative to traditional retail formats (such as department and high-street stores) which allow direct personal contact [3], [26]. Unfavorable shopper orientation can, therefore, be interpreted as a demand-side obstacle factor, so that under our assumptions survey data on this variable would translate into information regarding a notionally matching supply-side hurdle to Internet $\mathrm{B} 2 \mathrm{C}$ e-commerce. To test its empirical significance, we propose the following hypothesis.

$H 4$. Individual intentions not to shop online are stronger the higher the proportion of shoppers seeking social interaction interpreted as a demand-side obstacle factor is. Translating in terms of the survey data, the notionally matching supply-side hurdle facing Internet $\mathrm{B} 2 \mathrm{C}$ e-commerce would then become higher.

\section{Low Consumer Awareness}

Individuals would be little disposed to shop online if they do not possess good knowledge about how it works, or about the nature of its net benefits. In particular, it has been suggested that inadequate education and advertising regarding Internet B2C e-commerce would lead to "lack of consumer awareness" and weak and slow market acceptance [25]. Interpreting knowledge requirements as a demand-side obstacle factor, under our assumptions survey data on this variable would translate into information regarding a notionally matching supply-side hurdle to Internet $\mathrm{B} 2 \mathrm{C}$ e-commerce. To test its empirical importance, we propose the following hypothesis.

H5. Individual intentions not to shop online are stronger the lower consumer awareness interpreted as a demand-side obstacle factor is. Translating in terms of the survey data, the notionally matching supply-side hurdle facing Internet B2C e-commerce would then become higher.

Since lack of knowledge may induce higher perceived risk, we were careful to separate items relating to online transaction insecurity and consumer awareness in our questionnaire. Interestingly, a recent survey found Hong Kong to be lagging behind in Internet knowledge, with $86 \%$ of the respondents admitting that they should like to know more compared to an average of $67 \%$ over a sample of developed countries [41].

\section{RESEARCH MethodOLOGY}

We follow Bagozzi [4] and present a framework to relate consumer unwillingness and the supply-side hurdles presented under Hypotheses H1(a)-H5 (Fig. 1). The dependent variable is individual unwillingness to e-shop over the Internet, assumed to be harbored relatively to corresponding close-substitute aspects of traditional shopping as given reference points. On the other side of the framework, we begin with the relationships between consumer intentions not to shop online and (demand-side) obstacle factors in the form of perceptions of poor e-vendor performance, transaction insecurity, privacy concerns, and orientation toward social interaction and low awareness on the part of shoppers, again with corresponding close-substitute aspects of traditional shopping adopted as given reference points. Under our assumptions, survey data on these obstacle factors translate into information regarding notionally matching supply-side hurdles, which then enter the framework as equivalent independent variables. In this way, we obtain an analytically grounded 
Hla, b, c, d, e

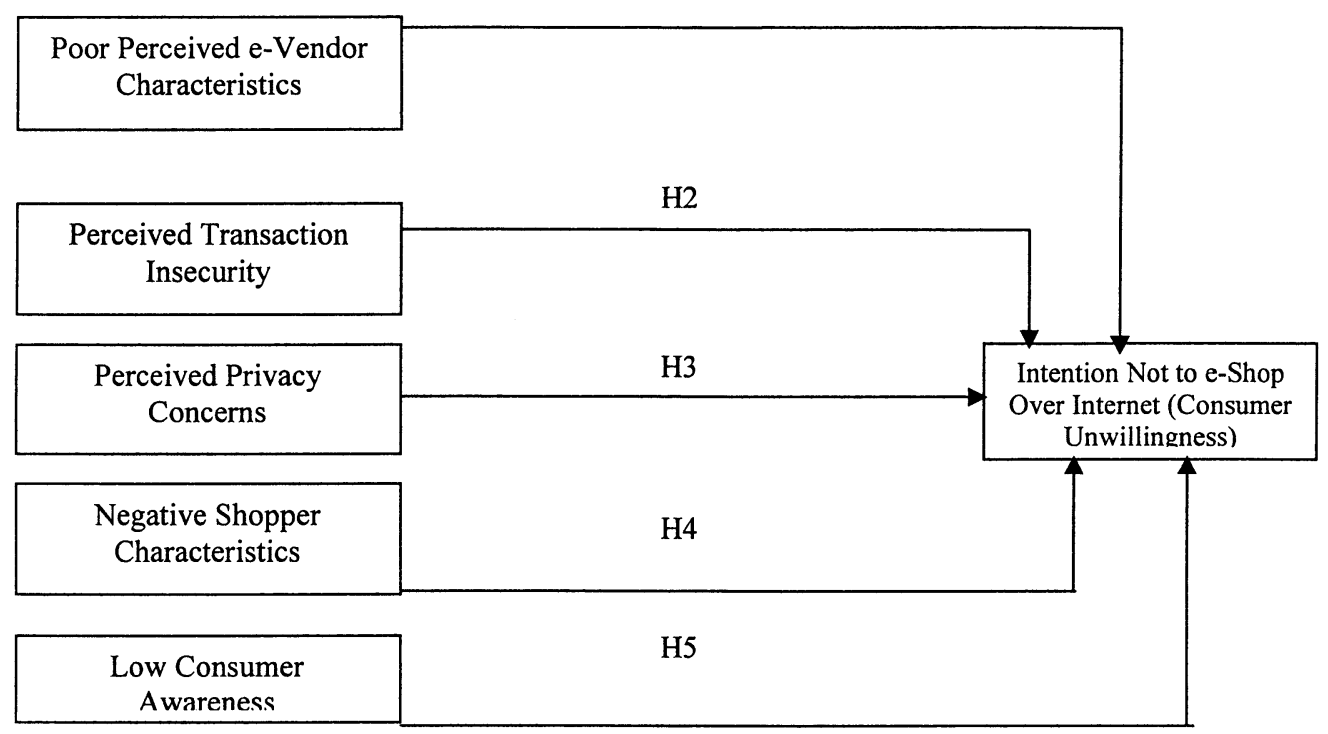

Fig. 1. Theoretical framework of supply-side hurdles to Internet B2C e-commerce.

and empirically testable framework to characterize the potential supply-side hurdles facing Internet B2C e-market development, under the assumptions and ceteris paribus conditions presented in Section I.

It should be pointed out that within our research project into e-business, two surveys were conducted over a sample of 500 Hong Kong residents classified by age, income, education, IT knowledge, and Internet experience. In the first exercise, the effects of geography (physical size of the market for consumer goods) and geographically related supply-chain costs were explicitly excluded, and the questions were presented in the positive sense. In the second exercise, these two considerations were included and the questions were framed in the negative sense. Commensurate with the objective of exploring supply side problems in Internet B2C e-commerce, data from the second survey were employed in this paper.

Table I summarizes the salient features of our questionnaire and survey instruments in the exercise. In addition to the suppositions noted in Section I, we requested individuals to respond under the notion that the requirements in question are technologically feasible. In this case, any absence of desiderata on the supply side can be attributed to operational and organizational failure on the part of the Internet e-shops. Meaningful data were obtained from 138 respondents out of the sample of 500 individuals, producing a response rate of $28 \%$. Survey questions were wholly predetermined following standard approach [1], with the questionnaire being divided into two sections.

The first section contains questions measuring the strength in which perceptions of poor e-vendor performance, transaction insecurity, privacy concerns, unfavorable shopper orientation and low consumer awareness affect the unwillingness to e-shop over the Internet. The second section was devoted to background and demographic matters. As noted in Section I, the survey responses can be interpreted to reflect notional demand-supply equilibrium in the case of consumer perceptions or exogenous effects in the case of shopper characteristics. Since the asymmetry in technical knowledge between seasoned Internet users and Internet e-firms is relatively small in a technologically following economy like Hong Kong, our respondents possessed sufficiently clear ideas about the performance levels which can be expected from the supply side. Further support is, therefore, indicated for the previous observation.

Respondents were requested to evaluate the questionnaire items on a standard seven-point Likert scale ranging from " $1 "=$ strongly disagree or very unimportant to "7" = strongly agree or very important [1]. The Likert scores were combined and tabulated (Table II), after which they were subjected to reliability evaluation and regression analysis. In the first case, we employed Cronbach's analysis to validate the internal consistency of the survey questions and instruments, and to test data reliability. Following Kyeong and Mee [25], reliability was assumed whenever Cronbach's $\alpha$ was greater than 0.6. As shown in Table III, the items in question were all found to be Cronbach-reliable by this criterion. The computations also demonstrated that internal consistency exists in the survey data pertaining to perceived poor shopping comparability, shopping inconvenience, low empathy, low tangibility, information uselessness, transaction insecurity, privacy concerns, unfavorable shopper characteristics, and low consumer awareness. Finally, it should be noted that our survey essentially involved transforming normal positive questions (e.g., regarding perceived usefulness) into negative questions (e.g., regarding perceived unusefulness). Since the starting point of this approach is grounded in standard methodology, additional validation of the survey items was deemed to be unnecessary.

\section{EMPIRICAL RESULTS AND DISCUSSION}

Given the reliability of the survey data, regression analysis was introduced to estimate the relationship between individual 
TABLE I

SUMMARY CONTENTS OF THE SURVEY QUESTIONNAIRE

\begin{tabular}{|c|c|c|}
\hline Variable & Description & \\
\hline \multirow{13}{*}{$\begin{array}{l}\text { Perceptions of poor } \\
\text { e-vendor Characteristics }\end{array}$} & \multirow{3}{*}{ Poor shopping comparability } & difficult to compare products \\
\hline & & difficult to compare prices \\
\hline & & long time for comparisons \\
\hline & \multirow[t]{3}{*}{ Inconvenience } & difficult to find products \\
\hline & & search function inflexible \\
\hline & & difficult to cancel orders \\
\hline & \multirow[t]{2}{*}{ Lack of empathy } & limited customer services \\
\hline & & limited after-sales services \\
\hline & \multirow[t]{2}{*}{ Uselessness of information } & scanty product information \\
\hline & & inaccurate product information \\
\hline & \multirow[t]{3}{*}{ Lack of tangibility } & cannot touch products \\
\hline & & cannot feel products \\
\hline & & difficult to evaluate quality \\
\hline \multirow{6}{*}{$\begin{array}{l}\text { Perceived Insecurity of } \\
\text { Internet Transactions }\end{array}$} & Low legal protection & \\
\hline & $\begin{array}{l}\text { e-firm's demonstrations of } \\
\text { concern }\end{array}$ & \\
\hline & Confirmation responses & \\
\hline & Security statements & \\
\hline & Fraud & \\
\hline & Wrong products & \\
\hline \multirow{4}{*}{$\begin{array}{l}\text { Perceived Privacy } \\
\text { Concerns }\end{array}$} & Personal information & \\
\hline & Unsolicited e-mails & \\
\hline & $\begin{array}{l}\text { Misuse of credit card } \\
\text { information }\end{array}$ & \\
\hline & $\begin{array}{l}\text { Unauthorized use of credit } \\
\text { cards }\end{array}$ & \\
\hline \multirow[t]{2}{*}{ Shopper Characteristics } & Recreational shoppers & \\
\hline & Convenience shoppers & \\
\hline \multirow[t]{4}{*}{ Consumer Awareness } & $\begin{array}{l}\text { Knowledge of online } \\
\text { shopping }\end{array}$ & \\
\hline & $\begin{array}{l}\text { Lack of promotion of online } \\
\text { shopping }\end{array}$ & \\
\hline & $\begin{array}{l}\text { Need of online shopping } \\
\text { tutorials }\end{array}$ & \\
\hline & $\begin{array}{l}\text { Insufficient knowledge of } \\
\text { online shopping procedures }\end{array}$ & \\
\hline $\begin{array}{l}\text { Intention not to e-shop } \\
\text { over Internet }\end{array}$ & $\begin{array}{l}\text { Difficulties buying from } \\
\text { Internet e-shops } \\
\text { Would not buy consumer } \\
\text { goods from Internet e-shops } \\
\text { if available from physical } \\
\text { shops }\end{array}$ & \\
\hline
\end{tabular}

unwillingness and supply-side hurdles under the framework of Fig. 1. We propose the following regression equation:

$$
\begin{aligned}
Y=\beta_{0}+ & \beta_{1} X_{1}+\beta_{2} X_{2}+\beta_{3} X_{3}+\beta_{4} X_{4}+\beta_{5} X_{5} \\
& +\beta_{6} X_{6}+\beta_{7} X_{7}+\beta_{8} X_{8}+\beta_{9} X_{9}+\mathrm{u}
\end{aligned}
$$

where

$\mathrm{Y}$ consumer unwillingness to e-shop over the Internet (as defined in Section I);

$X_{1} \quad$ perceived poor shopping comparability [as defined under H1(a)];

$X_{2}$ perceived shopping inconvenience [as defined under H1(b)];

$X_{3}$ perceived low empathy [as defined under H1(c)];
$X_{4}$ perceived low tangibility [as defined under H1(d)];

$X_{5} \quad$ perceived uselessness of information [as defined under $\mathrm{H} 1(\mathrm{e})]$;

$X_{6} \quad$ perceived transaction insecurity (as defined under $\mathrm{H} 2$ );

$X_{7}$ heightened perceived privacy concerns (as defined under $\mathrm{H} 3$ );

$X_{8} \quad$ (unfavorable) shopper orientation toward social interaction (as defined under $\mathrm{H} 4$ );

$X_{9} \quad$ low consumer awareness (as defined under H5).

This linear structure captures in an operationally convenient manner the relationships between supply-side hurdles and their joint effects on individual unwillingness to e-shop over the Internet. As noted in Section I (also see the following), the survey data were obtained on $\left\{X_{1}, \ldots, X_{9}\right\}$ as exogenous variables. 
TABLE II

DESCRIPTIVE STATISTICS (LIKERT SCORES)

\begin{tabular}{lcc}
\hline Variable & Mean & Std. Deviation \\
\hline Perceived poor shopping & 4.0217 & 1.1737 \\
comparability & & \\
Perceived inconvenience & 4.3056 & 1.1414 \\
Perceived low empathy & 4.3877 & 1.1621 \\
Perceived low tangibility & 6.1618 & 0.9326 \\
Perceived uselessness of & 3.8986 & 1.1175 \\
information & & \\
Perceived transaction insecurity & 5.1824 & 1.0135 \\
Perceived privacy concerns & 5.1793 & 1.2381 \\
Shopper social interaction & 3.9203 & 1.5849 \\
orientation & & \\
Low consumer awareness & 3.4740 & 1.2026 \\
\hline
\end{tabular}

Equation (1) can, therefore, be interpreted as a reduced form, thereby excluding the possibility of endogenous regressor or simultaneous equation bias in ordinary least squares (OLS) estimation.

\section{A. Overall Results}

OLS regression results are presented in Table IV. The $F$ value of $19.260(P=0.000)$ supports the conclusion that overall, (1) provides a statistically significant fit to the data. Though the regression $R^{2}$ of 0.57 indicates that $43 \%$ of the data variation was unexplained, this result can be interpreted by referring to the influential argument that the effects of technological change can be fruitfully analyzed in terms of demand and supply [12]. Given that under the present approach actual demand and supply factors such as price and cost differentials and the life-content of shopping [26] were deliberately excluded from the regression equation, a relatively low $R^{2}$ is, therefore, what should be expected. (Interestingly, our $R^{2}$ value suggests that in a more complete general equilibrium model of Internet B2C e-commerce, demand-side and supply-side considerations would affect consumer intentions with approximately equal weights). It should also be noted that though actual demand and supply variables are excluded from the regression equation, since they are independent of the supply-hurdle variables $\left\{X_{1}, \ldots, X_{9}\right\}$ and are, therefore, orthogonal to the latter, the OLS estimators $\left\{b_{0}, b_{1}, \ldots, b_{9}\right\}$ remain unbiased [21].

Though as a result the disturbance variance in (1) is over-estimated in the mean [21], any downward bias in the $t$ statistic does not affect statistical inference in the cases of interest, in which particular hypotheses presented in Section III are supported by the data. To see this, let us write $t_{C}$ for the $t$-value computed from the regression, which would in turn provide the lower limit of the integral determining the corresponding (computed) $P$-value in terms of the biased sampling distribution of $t_{C}$, say $P_{C}$. Though the biased sampling distribution of $t_{C}$ is unknown, given a sample size $=138$ it would be valid to replace the true $t$ distribution by the normal distribution. More- over, the realization (in the random variable sense) of any pair of computed and true values $t_{C}$ and $t^{*}$ must occur together, with $t_{C}<t^{*}$ because of the downward bias. Following Khuri [24], we can proceed to approximate the biased sampling distribution of $t_{C}$ in terms of the standard normal distribution $N(z)$ and a cubic spline segment-function in the neighborhood of $t_{C}$, with $t_{C}=t^{*}+h$ and $h<0$.

It follows that $P_{C}-P^{*}=N^{\prime}\left(z_{C}\right) h+\left(N^{\prime \prime}\left(z_{C}\right) h^{2} / 2\right)+$ $\left(N^{\prime \prime \prime}\left(z_{C}\right) h^{3} / 6\right)$, where $P^{*}$ is the $P$-value calculated from the true $t$ distribution using the computed $t_{C}$ and $z_{C}=t_{C} / \sqrt{ }(137 / 135) \cong t_{C}$. The choice of standard critical levels ( $\alpha=2.5 \%$ or $5 \%$ ) in hypothesis testing instructs us to focus on the tail of $N(z)$ to the right (or left) of the inflection point. Given the shape of the standard normal distribution, we, therefore, have $N^{\prime}()<0,. N^{\prime \prime}()>0,. N^{\prime \prime \prime}()<$.0 in the approximation, so that (with $h<0, h^{2}>0, h^{3}<0$ ) $P_{C}>P^{*}$. Since $t^{*}>t_{C}$, the $P$-value calculated from the true $t$ distribution in terms of $t^{*}$, say $P^{* *}$, must be such that $P^{* *}<P^{*}$. In sum, it follows that if any null hypothesis $\beta_{j}=0$ in the regression model is rejected on the basis of a biased computed value $t_{C}\left(P_{C}<\alpha\right)$, a fortiori it would be rejected with respect to the true value $\left(P^{* *}<P^{*}<P_{C}<\alpha\right)$. In the opposite case where the null hypothesis $\beta_{k}=0$ is not rejected, however, though $P_{C}>\alpha$, since $P_{C}>P^{*}>P^{* *}$ an element of ambiguity would be present in the statistical inference.

\section{B. Hypotheses Testing and Interpretation}

From Table IV, the following conclusions follow from the regression analysis.

1) Perceived poor shopping comparability significantly increases (in the statistical sense) individual unwillingness to buy consumer goods over the Internet $\left(b_{1}=0.249, P=0.000\right)$.

2) Perceived shopping inconvenience significantly increases (in the statistical sense) individual unwillingness to buy consumer goods over the Internet $\left(b_{2}=0.345, P=0.000\right.$ ).

Interpreting unfavorable consumer perceptions of shopping comparability and shopping convenience as demand-side obstacle factors, our results imply the existence of empirically important (translated and notionally matching) supply-side hurdles to Internet B2C e-commerce in these areas. In sum, therefore, hypotheses $\mathrm{H} 1$ (a) and $\mathrm{H} 1$ (b) are supported by the survey data.

Individuals seeking comparative information on prices, products, and shops prefer greater convenience, speed, and opportunities to discover bargains and advantages before purchase. The Likert score for poor perceived shopping comparability (Table II: mean $=4.0217$, s.d. $=1.1737$ ) further supports the implication that, competition from traditional shops notwithstanding, Hong Kong's Internet e-vendors have not sufficiently catered to these requirements. One reason may be that since the Internet B2C e-market is still in an introductory stage, online product choice is limited. The ready accessibility of physical stores would tend to further shift perceived shopping comparability in their favor. As regards perceived shopping inconvenience, given easy physical market access and the intentional-mode life style of many Hong Kong consumers, any failure in this respect would deter individual willingness from e-shopping over the Internet. These findings may explain a recent report that "business-to-consumer 
TABLE III

RESULTS OF RELIABILITY ANALYSIS

\begin{tabular}{|c|c|c|c|}
\hline & Sample size & Number of items & Cronbach $\alpha$ \\
\hline $\begin{array}{l}\text { Perceived poor } \\
\text { shopping } \\
\text { comparability }\end{array}$ & 138 & 3 & 0.902 \\
\hline $\begin{array}{c}\text { Perceived } \\
\text { inconvenience }\end{array}$ & 138 & 3 & 0.836 \\
\hline $\begin{array}{c}\text { Perceived low } \\
\text { empathy }\end{array}$ & 138 & 2 & 0.798 \\
\hline $\begin{array}{c}\text { Perceived low } \\
\text { tangibility }\end{array}$ & 138 & 3 & 0.633 \\
\hline $\begin{array}{c}\text { Perceived } \\
\text { uselessness of } \\
\text { information }\end{array}$ & 138 & 2 & 0.680 \\
\hline $\begin{array}{l}\text { Perceived } \\
\text { transaction } \\
\text { insecurity }\end{array}$ & 138 & 6 & 0.923 \\
\hline $\begin{array}{l}\text { Perceived privacy } \\
\text { concerns }\end{array}$ & 138 & 4 & 0.856 \\
\hline $\begin{array}{c}\text { Shopper } \\
\text { characteristics }\end{array}$ & 138 & 2 & 0.923 \\
\hline $\begin{array}{c}\text { Low consumer } \\
\text { awareness }\end{array}$ & 138 & 4 & 0.703 \\
\hline $\begin{array}{l}\text { Intention not to e- } \\
\text { shop over Internet }\end{array}$ & 138 & 3 & 0.667 \\
\hline
\end{tabular}

TABLE IV

REGRESSION RESULTS

\begin{tabular}{c|c|c|c}
\hline $\begin{array}{c}\text { Dependent } \\
\text { variable }\end{array}$ & $\begin{array}{c}\text { Independent } \\
\text { variable }\end{array}$ & $\begin{array}{c}\text { OLS coefficient } \\
\mathrm{b}_{\mathrm{k}}\end{array}$ & $P$-value \\
\hline \multirow{4}{*}{$\mathrm{Y}$} & $\mathrm{X}_{0}$ & -1.142 & 0.05 \\
\cline { 2 - 4 } & $\mathrm{X}_{1}$ & 0.249 & 0.000 \\
\cline { 2 - 4 } & $\mathrm{X}_{2}$ & 0.345 & 0.000 \\
\cline { 2 - 4 } & $\mathrm{X}_{3}$ & 0.008 & 0.91 \\
\cline { 2 - 4 } & $\mathrm{X}_{4}$ & -0.008 & 0.929 \\
\cline { 2 - 4 } & $\mathrm{X}_{5}$ & -0.027 & 0.704 \\
\cline { 2 - 4 } & $\mathrm{X}_{6}$ & 0.180 & 0.023 \\
\cline { 2 - 4 } & $\mathrm{X}_{7}$ & 0.189 & 0.007 \\
\cline { 2 - 4 } & $\mathrm{X}_{8}$ & 0.185 & 0.000 \\
\cline { 2 - 4 } & $\mathrm{X}_{9}$ & 0.131 & 0.038 \\
\hline
\end{tabular}

commerce was not catching on in Hong Kong" [40] and why, despite its high-technology organization, Admart failed in the face of competition from traditional supermarkets with widespread branch networks and strategically located small grocery shops.

3) Greater perceived transaction insecurity significantly increases (in the statistical sense) individual unwillingness to e-shop over the Internet $\left(b_{6}=0.18, P=0.023\right)$.

4) Heightened perceived privacy concerns significantly increases (in the statistical sense) individual unwillingness to e-shop over the Internet $\left(b_{7}=0.189, P=0.007\right)$.

Interpreting perceived transaction insecurity and perceived privacy concerns as demand-side obstacle factors, these results imply the existence of empirically important (translated and notionally matching) supply-side hurdles to Internet B2C e-com- merce in these areas. In sum, therefore, hypotheses $\mathrm{H} 2$ and $\mathrm{H} 3$ are supported by the survey data.

Since it is indicated that privacy is an important consideration in Internet usage, our results contribute empirical evidence to research on consumer concerns in this area [30], [37]. Although e-vendors frequently claim safety in Internet transactions perceived insecurity was found to be high (Table II: mean Likert score $=5.182$, s.d. $=1.0135)$, further supporting the implication that consumers in Hong Kong are particularly anxious about safety when buying online. Computer-related criminal offenses in Hong Kong-which mostly involved hacking and obtaining property by deception-rose more than $700 \%$ by value in the one year from 2000 to 2001 [42], [44]. In the light of such figures, the finding that perceived transaction insecurity and perceived privacy concerns represent important deterrents to consumer willingness comes as no surprise.

5) Shopper orientation toward social interaction significantly increases (in the statistical sense) individual unwillingness to e-shop over the Internet $\left(b_{8}=0.185, P=0.000\right)$. It follows that if the proportion of recreational consumers is high, an empirically important (translated and notionally matching) supply-side hurdle would emerge to hinder the development of Internet B2C e-commerce. Hypothesis $\mathrm{H} 4$ is, therefore, supported by the survey data.

6) Low consumer awareness significantly increases (in the statistical sense) individual unwillingness to e-shop over the Internet $\left(b_{9}=0.131, P=0.038\right)$. Interpreting knowledge inadequacy as a demand-side obstacle factor, our results imply the existence of an empirically important (translated and notionally matching) supply-side hurdle to Internet B2C e-market development in this direction. Hypothesis H5 is, therefore, supported by 
the survey data. This finding can be partly or wholly explained by a characteristic of Hong Kong consumers we observed during the survey-they are not adventurous and are conservative toward high-technology shopping. As a result, scanty knowledge of online shopping tends to instil a strong feeling that the individual is not in control. Subject to further investigation, we suggest that (other things being equal) the more acute is this perception the slower would be the market acceptance of Internet B2C e-shopping. Given the rapid diffusion of IT knowledge, however, the effects of low consumer awareness are not likely to persist. Though the present result is at variance with Kyeong and Mee [25], the difference is, therefore, likely to vanish with time.

7) With regard to low perceived empathy $\left(b_{3}=0.008, P=\right.$ $0.91)$, low perceived tangibility $\left(b_{4}=-0.008, P=0.929\right)$, and the perceived uselessness of information $\left(b_{5}=-0.027\right.$, $P=0.704)$, the $P$ values in each case were found to be greater than the 5\% and $2.5 \%$ levels of significance. Hypotheses H1(c), $\mathrm{H} 1(\mathrm{~d})$, and H1(e) are, therefore, not supported by the survey data. Interpreting perceived poor e-vendor performance with regard to empathy, tangibility, and usefulness of information as demand-side obstacle factors, our results imply that empirically important (translated and notionally matching) supply-side hurdles are not present to hinder the development of Internet B2C e-commerce. However, it should be pointed out that the previous cases, in which the null hypotheses $\beta_{3}=0, \beta_{4}=0$, and $\beta_{5}=0$ are not rejected by the data, are subject to the ambiguity in statistical inference discussed in Section V.1. Given the large $P$-values in question, this caveat is especially noteworthy.

Our result regarding e-vendor information differs from Swaminathan et al. [45]. In addition to ambiguous statistical inference, one reason may be that people in Hong Kong already enjoy ready access to comprehensive consumer product information through traditional channels such as advertising, magazines, or simply by easy rummaging in neighborhood shops. The Internet is, therefore, just one more way to search for product information. In such a situation, it is not surprising to find that the information supplied by Internet e-vendors exerts a slight impact on consumer intentions. This would especially be the case at the outset, when online product variety is relatively limited. As regards low perceived empathy and low perceived tangibility, though the ratings obtained from the survey respondents were high (more negative) in this regard (Table II: mean Likert scores $=4.3877$ and 6.1618 , respectively), regression analysis showed that these perceptions did not materially affect unwillingness. Though this finding is opposite to Vellido et al. [49], one reason (in addition to ambiguity in statistical inference) may lie in the things consumers currently prefer to buy online in Hong Kong - particularly small household goods, groceries, and entertainment tickets [40]. Empathy and tangibility with regard to such products are not so important as compared to clothing and footwear, which are popularly purchased over the Internet elsewhere. It is, therefore, not out of place to find that in Hong Kong, consumers worry little about empathy and tangibility when deciding whether or not to shop online. The implication follows, however, that when product popularity changes, so would the importance attached to these two factors.
Following Liao and Cheung [26], setup and other supply-related costs of Internet access and usage are parametrized in the constant in (1). The regression result $b_{0}=-1.142, P=0.05$ (Table II) and its negative sign can, therefore, be readily interpreted. In particular, a rise in any of the parametric magnitudes would increase the opportunity cost of not exploiting the Internet more fully, which would in turn reduce individual intentions not to e-shop over this medium.

\section{MANAGEMENT IMPLICATIONS AND CONCLUDING OBSERVATIONS}

This paper suggests that empirically significant supply-side hurdles exist to hinder the development of Internet B2C e-commerce in technologically-following economies like Hong Kong. Demand-side obstacle factors in the form of perceived poor shopping comparability, shopping inconvenience, transaction insecurity, privacy concerns, orientation toward social interaction and low awareness on the part of consumers imply that serious potential supply-side problems exist for Internet e-firms, especially at the outset. Unless these issues are addressed in the immediate future, the likelihood of successful Internet B2C e-market take-off would be small.

Though the different supply-side hurdles present problems for marketing, innovation, and engineering managers in Internet e-firms, in many cases the answers are implied in part or in whole by our findings. Economic reasoning suggests that comparative advantage conferred by the Internet must be exploited to create value over traditional competitors. This is especially the case along the directions and order of priority indicated by the statistical significance of the regression coefficients $b_{k}(k=$ $1, \ldots, 9)$, which can be usefully interpreted as impact multipliers of management initiatives to reduce supply-side hurdles. With regard to perceived shopping inconvenience, this suggests focusing on items with low brick-and-mortar accessibility, coordinated with well-organized and comprehensive online product categorization and user-friendly consumer-vendor interfaces. Ideally, it should require only a few mouse-clicks to locate any item of interest and view it onscreen. As shown in Fig. 2, the impact multiplier of such an initiative is estimated to be $35 \%$ $\left(b_{2}=0.345\right)$, thereby ranking it first in order of effect (other things being equal).

Perceived shopping comparability can be improved by greater variety in product choice over the Internet (in the midst of product line specialization) and by reducing the time and effort to obtain comparative information, e.g., through the introduction of virtual displays designed to enable individuals to quickly and meaningfully compare goods and services. On-site promotions and sequenced recommendations (the week's top lines in terms of sales, replacement dates, forthcoming innovations, and so on) would increase the e-storefront's attractiveness and titillate the desire to buy. Since consumer-vendor interaction in the case of goods requiring "touch and feel" handling before purchase is not as immediate or as real compared to the shop counter, comparative advantage considerations suggest that Internet e-firms should concentrate on things which suffer least from quality uncertainty under asymmetrical information (the "lemon" problem). From Fig. 2, the estimated impact 


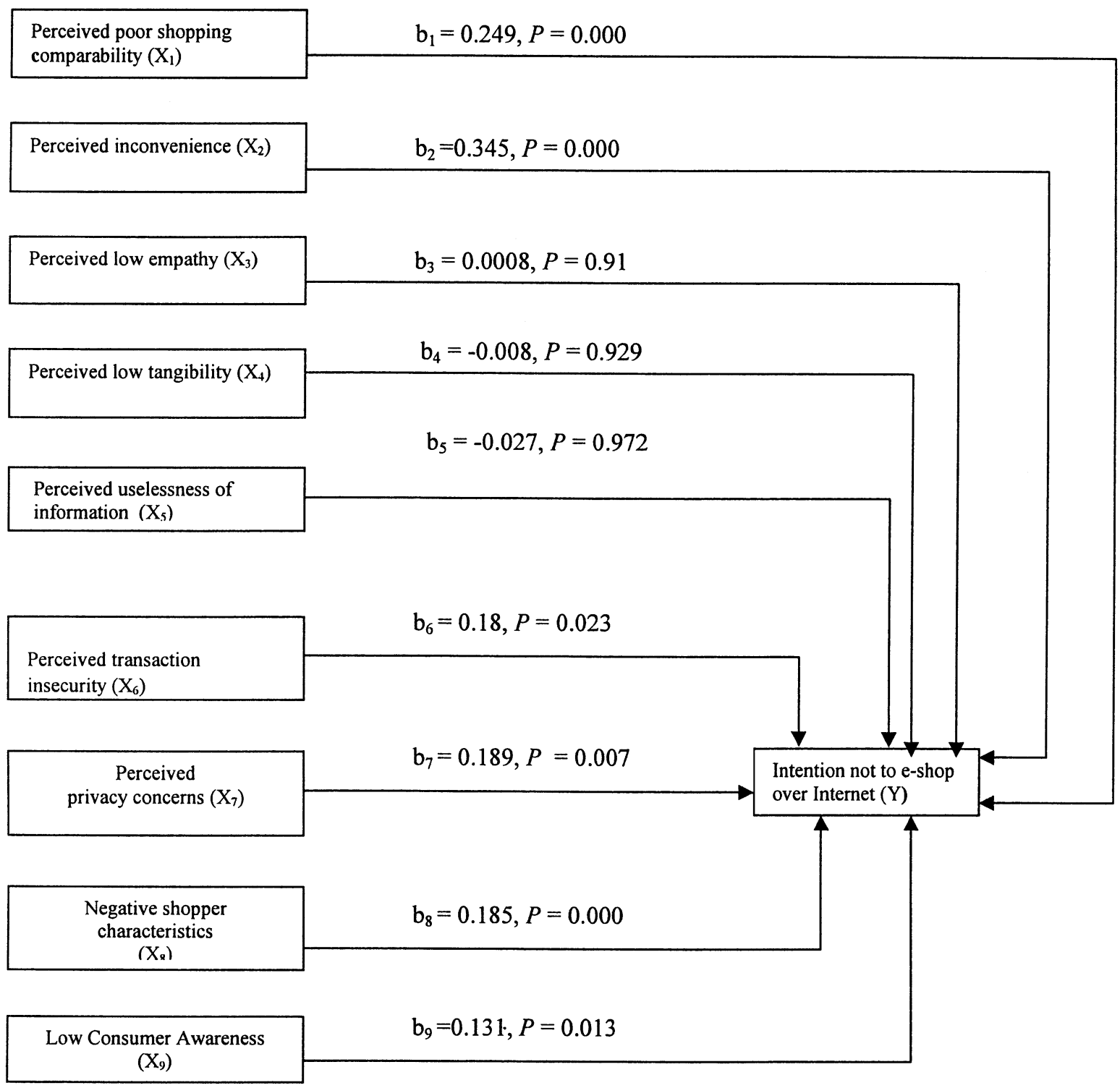

Fig. 2. Empirical framework of supply-side hurdles to Internet B2C e-commerce.

multiplier associated with perceived shopping inconvenience is $25 \%\left(b_{1}=0.249\right)$, so that efforts to reduce this supply-side hurdle rank second in order of effect (other things being equal).

The empirical significance of perceived transaction insecurity and perceived privacy concerns carries the lesson that it is imperative for the Internet e-shop to increase safety, particularly over the protection of personal and financial information and the accurate processing and delivery of orders. A campaign to advertise the ready availability and effectiveness of safeguards and guarantees would be useful, the more so if support is forthcoming from banks and the monetary authorities. From Fig. 2, it is seen that the impact multipliers in question are estimated to be about $20 \%$ ( $\left.b_{6}=0.18, b_{7}=0.189\right)$, jointly ranking them third in order of effect (other things being equal).

Our empirical findings regarding the significance of shopper characteristics should prove useful to managers planning to segment the market, retain and enhance client loyalty, and target prospective customers, and also for the ultimate introduction of one-to-one e-shopping over the Internet. In particular, the intro- duction of discussion clubs and chat rooms serviced by dedicated customer relation officers would be effective ways to enhance the social interaction aspect of Internet e-shopping. Fig. 2 shows that the estimated impact multiplier of such an effort is close to $20 \%\left(b_{8}=0.185\right)$, translating to third position in order of effect (other things being equal).

To increase consumer awareness, the Internet vendor can distribute free e-shopping guides and promote its advantages through hands-on demonstrations in booths and stalls strategically located along high street (especially next to large traditional department stores). From Fig. 2, the impact multiplier of an initiative of this nature is estimated to be $13 \%$ $\left(b_{9}=0.131\right)$ : viz. fourth in order of effect (other things being equal).

Interestingly, Fig. 2 shows that efforts on the part of Internet e-firms to reduce perceived transaction insecurity and perceived privacy concerns and to shift shopper orientation in their favor are approximately equal in impact on consumer unwillingness (20\%). Since the survey data were obtained on the assumption 
of a notional supply side, cost features prominently among the ceteris paribus conditions attached to each impact-multiplier result. Further research can, therefore, be usefully directed to establishing whether and how the order of effectiveness among the different management initiatives would change when marginal costs are taken into account. In the same way, it would be interesting for further research to pursue the question of whether estimates of the impact multipliers (regression coefficients) would vary as the time, place, and data vary. The answer may allow us to further understand the special situation of small technologically-following open economies like Hong Kong.

Our regression results yield an implication of particular interest to engineering managers. The coefficient ratios $b_{j} / b_{k}$ allow numerical comparison between the different supply-side hurdles (as defined) in terms of the marginal rates of substitution $\operatorname{MRS}_{k} j(j, k=1, \ldots, 9, k \neq j)$, under the ceteris paribus condition that consumer unwillingness is held constant [27]. In particular, MRS estimates yield operational information regarding the substitutability of improvements with regard to different supply-side hurdles. For example, holding consumer unwillingness constant, if the Internet e-firm is able to bring about a reduction in poor perceived shopping comparability $\left(X_{1}\right)$, this would be equivalent in effect to an increase in perceived shopping inconvenience $\left(X_{2}\right)$ given by $M R S_{21}=b_{1} / b_{2}=0.72$.

Combined with accounting data, MRS calculations would allow the Internet e-firm to determine the benefits of an effort to incrementally mitigate a given supply-side hurdle in the medium run, relative to the cost of doing so. The economic-engineering efficiency principle of equal technical and financial substitution at the margin can then be given numerical content without the problem of estimating the Internet e-firm's production function, which (as is generally the case in technology-based innovations) would involve difficult-to-measure output displaying qualitative as well as quantitative characteristics. In particular, since data on supply-side hurdles were translated from survey responses regarding negative individual perceptions and unfavorable shopper characteristics interpreted as obstacle factors, consumer unwillingness conveniently enters as a scalar proxy for many-dimensional output in MRS calculations. Estimates of the MRS between the remaining supply-side hurdles are displayed in Table V. By virtue of significant empirical support, supply-side changes initiated by the Internet e-firm on the basis of this information are more likely to be viewed as a rational effort to reduce obstacle factors on the demand side, and so would be met with an increase in consumer unwillingness.

Though the management initiatives discussed previously involve the allocation of substantial resources to the Internet e-firm's marketing, innovation, and engineering departments, the costs involved are not likely to be prohibitive for technologically-following organizations. This consideration notwithstanding, the transfer and adoption of technology must be appropriate to the applications at hand. In particular, systems designed in technologically-leading areas like the U.S. and the European Union for use in geographically large markets do not necessarily represent optimal choices when imported into physically small economies like Hong Kong. (This is the subject of parallel research conducted on the basis of data
TABLE V

MRS BETWEEN EMPIRICALLY SIGNIFICANT SUPPLY-SIDE HURDLES

\begin{tabular}{|c|c|}
\hline Variables & $\mathrm{MRS}_{\mathrm{kj}}$ \\
\hline $\begin{array}{l}\text { Perceived inconvenience }\left(\mathrm{X}_{2}\right) \text { : Perceived poor } \\
\text { shopping comparability }\left(\mathrm{X}_{1}\right)\end{array}$ & $\mathrm{MRS}_{21}=\mathrm{b}_{1} / \mathrm{b}_{2}=0.721$ \\
\hline $\begin{array}{l}\text { Perceived transaction insecurity }\left(\mathrm{X}_{6}\right) \text { : Perceived } \\
\text { poor shopping comparability }\left(\mathrm{X}_{1}\right)\end{array}$ & $\mathrm{MRS}_{61}=\mathrm{b}_{1} / \mathrm{b}_{6}=1.383$ \\
\hline $\begin{array}{l}\text { Perceived privacy concerns }\left(X_{7}\right) \text { : Perceived poor } \\
\text { shopping comparability }\left(X_{1}\right)\end{array}$ & $\mathrm{MRS}_{71}=b_{1} / b_{7}=1.317$ \\
\hline $\begin{array}{l}\text { Shopper social interaction orientation }\left(\mathrm{X}_{8}\right) \text { : } \\
\text { Perceived poor shopping comparability }\left(\mathrm{X}_{1}\right)\end{array}$ & $\mathrm{MRS}_{81}=b_{1} / b_{8}=1.346$ \\
\hline $\begin{array}{l}\text { Low consumer awareness }\left(\mathrm{X}_{9}\right) \text { : Perceived poor } \\
\text { shopping comparability }\left(\mathrm{X}_{1}\right)\end{array}$ & $\mathrm{MRS}_{91}=\mathrm{b}_{1} / \mathrm{b}_{9}=1.901$ \\
\hline $\begin{array}{l}\text { Perceived transaction insecurity }\left(\mathrm{X}_{6}\right) \text { : Perceived } \\
\text { shopping inconvenience }\left(\mathrm{X}_{2}\right)\end{array}$ & $\mathrm{MRS}_{62}=\mathrm{b}_{2} / \mathrm{b}_{6}=1.917$ \\
\hline $\begin{array}{l}\text { Perceived privacy concerns }\left(X_{7}\right) \text { : Perceived } \\
\text { shopping inconvenience }\left(X_{2}\right)\end{array}$ & $\mathrm{MRS}_{72}=\mathrm{b}_{2} / \mathrm{b}_{7}=1.825$ \\
\hline $\begin{array}{l}\text { Shopper social interaction orientation }\left(\mathrm{X}_{8}\right) \text { : } \\
\text { Perceived shopping inconvenience }\left(\mathrm{X}_{2}\right)\end{array}$ & $\mathrm{MRS}_{82}=\mathrm{b}_{2} / \mathrm{b}_{8}=1.865$ \\
\hline $\begin{array}{l}\text { Low consumer awareness }\left(\mathrm{X}_{9}\right) \text { : Perceived shopping } \\
\text { inconvenience }\left(\mathrm{X}_{2}\right)\end{array}$ & $\mathrm{MRS}_{92}=\mathrm{b}_{2} / \mathrm{b}_{9}=2.634$ \\
\hline $\begin{array}{l}\text { Perceived privacy concerns }\left(\mathrm{X}_{7}\right) \text { : Perceived } \\
\text { transaction insecurity }\left(\mathrm{X}_{6}\right)\end{array}$ & $\mathrm{MRS}_{76}=\mathrm{b}_{6} / \mathrm{b}_{7}=0.952$ \\
\hline $\begin{array}{l}\text { Shopper social interaction orientation }\left(\mathrm{X}_{8}\right) \text { : } \\
\text { Perceived transaction insecurity }\left(\mathrm{X}_{6}\right)\end{array}$ & $\mathrm{MRS}_{86}=\mathrm{b}_{6} / \mathrm{b}_{8}=1.021$ \\
\hline $\begin{array}{l}\text { Low consumer awareness }\left(\mathrm{X}_{9}\right) \text { : Perceived } \\
\text { transaction insecurity }\left(\mathrm{X}_{6}\right)\end{array}$ & $\mathrm{MRS}_{96}=\mathrm{b}_{6} / \mathrm{b}_{9}=1.374$ \\
\hline $\begin{array}{l}\text { Shopper social interaction orientation }\left(\mathrm{X}_{8}\right) \text { : } \\
\text { Perceived privacy concerns }\left(\mathrm{X}_{7}\right)\end{array}$ & $\mathrm{MRS}_{87}=\mathrm{b}_{7} / \mathrm{b}_{8}=1.021$ \\
\hline $\begin{array}{l}\text { Low consumer awareness }\left(\mathrm{X}_{9}\right) \text { : Perceived privacy } \\
\text { concerns }\left(\mathrm{X}_{7}\right)\end{array}$ & $\mathrm{MRS}_{97}=\mathrm{b}_{7} / \mathrm{b}_{9}=0.721$ \\
\hline $\begin{array}{l}\text { Low consumer awareness }\left(\mathrm{X}_{9}\right) \text { : Shopper social } \\
\text { interaction orientation }\left(\mathrm{X}_{8}\right)\end{array}$ & $\mathrm{MRS}_{98}=\mathrm{b}_{8} / \mathrm{b}_{9}=0.721$ \\
\hline
\end{tabular}

from our first survey: see Section III.) Finally, it should be noted that since traditional shopping is introduced as a given reference position in the discussion, further effort is required to introduce it as an endogenous variable in a general analysis of consumer behavior in the market for consumer goods. In particular, innovations on the part of traditional shops would create additional (and higher) supply-side hurdles for Internet B2C e-firms, requiring even more intensive efforts from the latter to compete.

\section{ACKNOWLEDGMENT}

The authors would like to thank W. Zangwill, University of Chicago, Chicago, IL, the Guest Editors, and two anonymous referees for their helpful comments and criticisms.

\section{REFERENCES}

[1] D. A. Aaker, V. Kumar, and G. S. Day, Marketing Research, 7th ed. New York: Wiley, 2001.

[2] G. Akerlof, "The market for 'Lemons': quality uncertainty and the market mechanism," Quart. J. Econ., vol. 84, pp. 488-500, Aug. 1970.

[3] J. Alba, J. Lynch, B. Weitz, C. Janiszcwski, R. Lutz, A. Sawyer, and S. Wood, "Interactive home shopping: consumer, retailer and manufacturer incentives to participate in electronic marketplaces," J. Market., vol. 61, no. 3, pp. 38-54, 1997. 
[4] R. P. Bagozzi, "Marketing as an exchange," J. Market., vol. 39, no. 3, pp. 32-39, 1975.

[5] D. N. Bellenger and P. K. Kargaonkar, "Profiling the recreational shopper," J. Retail., vol. 56, no. 3, pp. 77-82, 1980 .

[6] M. Blodgett, "E-business and privacy for all?," $\mathrm{CIO}$, vol. 13, no. 13, pp. $100-104,2000$.

[7] L. F. Cranor, J. Reagle, and M. S. Ackerman. (1999) "Beyond concerns: Understanding net users' attitudes about online privacy" [Online]http: www.research.att.com/projects/privacystudy

[8] F. D. Davis, "Perceived usefulness, perceived ease of use, and user acceptance of information technology," MIS Quart., vol. 13, no. 3, pp. 319-340, 1989.

[9] F. D. Davis, R. P. Bagozzi, and P. R. Warshaw, "User acceptance of computer technology: A comparison of two theoretical models," Manage. Sci., vol. 35, no. 8, pp. 982-1003, 1989.

[10] P. Fitchtman, "Preventing credit card fraud and identity theft: A primer for online merchants," Information Systems Security, vol. 10, no. 5, pp. $51-59,2001$.

[11] K. C. Gehrt, L. J. Yale, and P. A. Lawson, "The convenience of catalog shopping: Is there more to it than time?," J. Dir. Market., vol. 10, no. 4, pp. 19-28, 1996.

[12] Z. Griliches, "Hybrid corn: An exploration in the economics of technological change," Econometrica, vol. 25, no. 4, pp. 27-52, 1957.

[13] M. Head and Y. Yuan, "Privacy protection in electronic commerce-a theoretical framework," Hum. Syst. Manage., vol. 20, no. 2, pp. 149-160, 2001.

[14] T. A. Hemphill, "Doubleclick and consumer online privacy: an e-commerce lesson learned," Bus. Soc. Rev., vol. 105, no. 3, pp. 361-372, 2000.

[15] D. L. Hoffman, T. P. Novak, and M. Peralta, "Building consumer trust online," Commun. ACM, vol. 42, no. 4, pp. 80-86, 1999.

[16] "Hong Kong lags behind in e-Commerce," Hong Kong iMail, Nov. 22, 2000.

[17] "Where Admart went wrong," Hong Kong iMail, Jan. 21, 2001.

[18] Information Service Department, Hong Kong Possesses Best Potential to Develop Electronic Business: Hong Kong Government, Nov. 24, 2000.

[19] "Security is all about business, not technology," Inform. Syst. Security, vol. 10 , no. 6, pp. 10-14, 2002.

[20] S. L. Jarvenpaa and P. A. Todd, "Consumer reactions to electronic shopping on the world wide web," Int. J. Electron. Commerce, vol. 1-2, pp. 59-88, Winter 1996.

[21] J. Johnston, Econometric Methods, 3rd ed. New York: McGraw-Hill, 1984.

[22] R. Kalakota and A. B. Whinston, Electronic Commerce. Reading, MA Addison-Wesley, 1997.

[23] E. P. Kelly, "Ethical aspects of managing customer privacy in electronic commerce," Hum. Syst. Manage., vol. 19, no. 4, pp. 237-244, 2000.

[24] A. I. Khuri, Advanced Calculus with Applications to Statistics. New York: Wiley, 1993.

[25] S. H. Kyeong and H. N. Mee, "Critical failure factors that discourage the growth of electronic commerce," Int. J. Electron. Commerce, vol. 2, pp. 25-43, Winter 1999.

[26] Z. Liao and M. T. Cheung, "Internet-based e-shopping and consumer attitudes: An empirical study," Inform. Manage., vol. 38, no. 5, pp. 299-306, 2001.

[27] — , "Internet-based e-Banking and consumer attitudes: An empirical study," Inform. Manage., vol. 39, no. 4, pp. 283-295, 2002.

[28] _ - "Do competitive strategies drive R\&D? An empirical investigation of Japanese high-technology corporations," J. High Technol. Manage. Res., vol. 13, no. 2, pp. 143-156, 2002.

[29] A. F. Luedi, "Personalize or perish," Electron. Market., vol. 7, no. 3, pp. 22-25, 1997.

[30] G. R. Milne and M. E. Gordon, "Direct mail privacy-efficiency trade-offs within an implied social contract network," J. Public Pol. Market., vol 12, no. 2, pp. 206-215, 1993.

[31] A. D. Miyazaki and A. Fernandez, "Consumer perceptions of privacy and security risks for online shopping," J. Consum. Affairs, vol. 35, no. 1, pp. 27-44, 2001

[32] C. Moorman, R. Deshpande, and G. Zaltman, "Factors affecting trust in marketing relationhships," J. Market., vol. 57, no. 1, pp. 81-101, 1993.

[33] K. Muralidhar, R. Sarathy, and R. Parsa, "An improved security requirement for data perturbation with implications for e-Commerce," Decision Sci., vol. 32, no. 4, pp. 683-698, 2001.

[34] D. Neeley, "The privacy principle," Sec. Manage., vol. 43, no. 4, pp 47-50, 1999.

[35] J. M. Peha, "Making the internet fit for commerce," Issues Sci. Technol., vol. 16 , no. 2 , pp. $72-79,1999 / 2000$.
[36] R. S. Poore, "Privacy and the value of personal data," Inform. Syst. Secur., vol. 9, no. 3, pp. 11-17, 2000

[37] A. J. Rohm and G. R. Milne, "Consumer's privacy concerns about direct marketer's use of personal medical information," in Proc. 1999 Association for Health Care Research Conf., J. F. Hair Jr., Ed., Breckenridge, CO, 1999.

[38] G. P. Schneider and J. T. Perry, Electronic Commerce, 2nd ed. Boston, MA: Thomson Learning, 2001.

[39] J. N. Sheth and A. Parvatiyar, "Relationship marketing in consumer markets: Antecedents and consequences," J. Acad. Market. Sci., vol. 23, pp. 255-271, Fall 1995.

[40] "Net shopping in Hong Kong fails to deliver," South China Morning Post, Oct. 10, 2000.

[41] "Shoppers own up to lack of net knowledge," South China Morning Post, Oct. 26, 2000

[42] "Cybercrime Study warns of mass victimization," South China Morning Post, Apr. 2, 2001.

[43] "More Hong Kong people log on to Internet," South China Morning Post, June 28, 2001

[44] "Online fraud in Hong Kong soars," South China Morning Post, Apr. 9, 2002.

[45] V. Swaminathan, E. Lepkowska-White, and B. P. Rao. (1999) Browers or buyers in cyberspace?, an investigation of the factors influencing electronic exchange. J. Comput.-Mediated Commun. [Online] http:www.ascusc.org/jcmc/vol5/issue2

[46] "Survey of Internet usage in Hong Kong" (in Chinese), Ta Kung Pao, June 7-8, 2000

[47] M. Tan and T. S. H. Teo, "Factors influencing the adoption of internet," Int. J. Electron. Comm., vol. 2, pp. 5-18, Winter 1998.

[48] E. Turban, J. Lee, D. King, and H. M. Chung, Electronic Commerce: A Managerial Perspective. Englewood Cliffs, NJ: Prentice-Hall, 2000.

[49] A. Vellido, P. J. G. Lisboa, and K. Meehan, "Quantitative characterization and prediction of on-line purchasing behavior: A latent variable approach,” Int. J. Electron. Comm., vol. 4, pp. 83-104, Summer 2000.

[50] T. Wang, S.-U. Guan, and T. K. Chan, "Integrity protection for code-ondemand mobile agents in e-commerce," J. Syst. Software, vol. 60, no. 3, pp. 211-221, 2002.

[51] P. Zellweger, "Web-based sales: Defining the cognitive buyer," Electron. Market., vol. 7, no. 3, pp. 10-16, 1997.

[52] V.Zwass, "Electronic commerce: Structures and issues," Int. J. Electron Comm., vol. 1, no. 1, pp. 3-23, 1996.

[53] Z. Griliches, Technology, Education, and Productivity. London, U.K.: Blackwell, 1957.

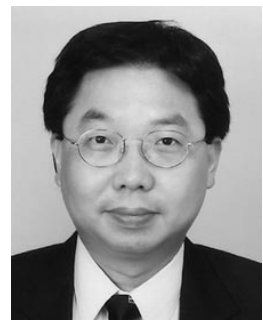

Michael Tow Cheung (M'03) received the Ph.D. degree from the University of London, London, U.K.

Currently, he is an Associate Professor with the School of Economics and Finance, University of Hong Kong, Pokfulam Road, Hong Kong. His research interests include mathematical modeling and the economics of $\mathrm{R} \& \mathrm{D}$, engineering, and e-commerce. He has written articles that have been published in Communications of the ACM, Information and Management, and Journal of High Technology Management Research.

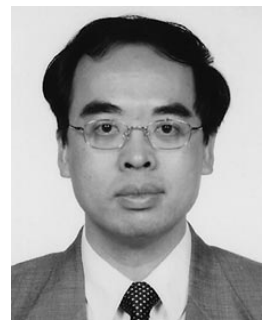

Ziqi Liao (M'93-SM'03) received the Ph.D. degree from the University of Queensland, Queensland, Australia.

He is currently an Associate Professor of Information Systems and Electronic Commerce with the Department of Finance and Decision Sciences, Hong Kong Baptist University, Kowloon, Hong Kong. He has been professionally associated with academic and research institutions in Australia, China, Japan, Singapore, and the United States, and served as a consultant to private companies, public organizations and United Nations Industrial Development Organization (UNIDO). He has authored articles published in the IEEE TRANSACTIONS ON ENGINEERING MANAGEMENT, Communications of the ACM, Information and Management, Systems Research and Behavioral Science, $R \& D$ Management, Journal of High Technology Management Research, International Journal of Innovation Management, and other internationally refereed research journals. His research areas include emerging technology management, information systems, electronic commerce, and supply chain management. 